\title{
Work of the Chemistry Research Board
}

$\mathrm{T}$ HE report of the Chemistry Research Board* drawn up by the present director, Prof. G. T. Morgan, surnmarises the work carried out in the Government Chemical Research Laboratory during the first ten years of its existence, and is an impressive record of a large amount of valuable research in various fields. Much of the work has an industrial bearing, and there has been useful collaboration with several firms, mernbers of the staffs of which have been attached to the laboratory. A list of more than a hundred published papers is given, together with particulars of some thirty patents.

The first part of the report deals with researches on the corrosion of metals, which have had reference to the mechanism of corrosion in its relation to the prevention of rusting, tarnishing and corrosion of metals in industrial use. An anodic oxidation process for aluminium, in which the metal is protected by an oxide film produced electrically, was worked out, and a means of colouring aluminium has been adopted in industry. The protection of magnesium and its alloys, which are used in the aircraft, motor-boat and automobile industries, against corrosion by seawater and motor fuels, is being studied, as well as the corrosion of locomotive boiler tubes, zinc and purified iron and steels.

The report then deals with high-pressure investigations, including the synthetic production of alcohols from carbon monoxide and hydrogen, and acetic acid from carbon monoxide and ethyl alcohol. The starting point of these syntheses is represented by materials obtainable from coal. The equipment recently constructed is designed for work at 3,000 atm. at a temperature of $200^{\circ} \mathrm{C}$.

New methods of carbonising coal have led to the production of tars which differ considerably from those familiar in industry. New methods of separation

* Department of Scientific and Industrial Research. Report of the Chemistry Research Board for the Period ended 31st December 1934 . with Historical Introduction and Report by the Director of Chemical Research. Pp. $\mathrm{v}+94$. (London: H.M. Stationery Office, 1935.) 1s. $6 d$. net. have made possible the identification and classification of the components of tars produced by various methods. Certain tars contain phenolic constituents readily separable by distillation, and these, in solution in caustic soda, form a very efficient and cheap wetting-out agent for use in the textile industry, which is now marketed under the name of 'shirlacrol'. The application of high-pressure technique to coal tars has produced new compounds which have been tested for possible use in the dye industry.

A large amount of work has been done on synthetic resins, and a tough transparent resin has been obtained which resembles glass and may find application as a material for artificial dentures. Experiments with the object of making synthetic resins direct from tar oils indicate the possibility of simultaneously separating the valuable hydrocarbon oils. Resins formed in this way have been used for impregnation purposes, as they prevent the growth of mildew.

Since 1931, work has been proceeding in co-operation with the British Road Tar Association for the improvement in the efficiency and quality of road tars. It has been found that light, as well as air, may be important in connexion with the life of tar applied to roads.

Several problems concerned with micro-organisms have been dealt with. A method of preparing acetone-alcohol mixtures, useful as liquid fuel and otherwise, from straws and waste vegetable matter by fermentation has been demonstrated, and other investigations in this branch include the effects of micro-organisms in the deterioration of fabries and in tainting live fish in rivers, and the degumming of silk by lower fungi instead of acids.

The preparation and testing of synthetic drugs in co-operation with the Medical Research Council, the production of a base-exchange material for water. softening from British clays, the action of drinking water on lead, and investigations of the rarer metals are other branches of work described in the report.

\section{Conifers of the Balipara Frontier Tract, Assam}

\footnotetext{
TN the Indian Forester of May 1935 (61, No. 5, 1 Civil and Military Gazette Press, Lahore), Dr. $\hat{N}$. L. Bor, of the Indian Forest Service and at present political officer, writes on "The Conifers of the Balipara Frontier Tract, Assam". As a forest officer in Assam, Dr. Bor has taken full advantage of exceptional opportunities to study the forest flora of the more unknown parts of the country; some of his best work in the almost unknown region of which he is now in charge is briefly described in the article under review. The flora of this section of the Himalaya was practically unknown up to recent times and he set to work to collect, the considerable results of his activities being now under examination at the Royal Botanic Garden, Sibpur.
}

The area of the Eastern Himalaya in question covers an enormous tract of country exhibiting every variety of climate from that of the sweltering plains of Assam to the arctic climate of the eternal snows. Its northern boundary is the lofty Sela Range which sweeps north-eastward from the Tibet-Bhutan border and divides the Balipara Frontier Tract from Tibet proper. It contains a number of peaks more than 21,000 feet in height. Several travellers, Bailey and Moreshead, Kingdon Ward and others, have crossed the Sela pass into Tibet, but the southern slopes to the east are unexplored.

Dr. Bor gives details of the configuration of the region, its extraordinarily variable climate, its geo. logical features and inhabitants. A study of the latter 